\title{
EVALUACION DE LOS PROCESOS SOCIOECONOMICOS DEL USO Y OCUPACION DEL TERRITORIO EN LA PROVINCIA DE PICOTA, SAN MARTÍN, PERÚ, 1980-2012
}

\author{
Séfora RODRÍGUEZ ${ }^{1,2}$; Ángel Martín RODRÍGUEZ DEL CASTILLO ${ }^{1}$, Jorge TORRES ${ }^{2,3}$, Luis ARÉVALO \\ LÓPEZ ${ }^{1}$,Alfredo ISUIZA ${ }^{1}$ \\ 1 Instituto de Investigaciones de la Amazonía Peruana IIAP. Programa de Investigación en Cambio Climático, Desarrollo \\ Territorial y Ambiente (PROTERRA) / Programa de Investigaciones en Biodiversidad Amazónica (PIBA), Sede San Martín, \\ Tarapoto,Perú.maria.sefora18@gmail.com; angelmartinrdc@gmail.com \\ 2 Universidad Alas Peruanas, Filial Tarapoto, San Martín, Perú. \\ 3 Centro de Investigación, Gestión y Consultoría Ambiental. CEICA. Tarapoto, San Martin, Perú.
}

\section{RESUMEN}

El presente estudio tuvo como finalidad evaluar los procesos socioeconómicos del uso y ocupación del territorio en la provincia de Picota, San Martín. Se determinaron las zonas de uso actual generadas por las actividades antrópicas y otros procesos en los diez distritos de la provincia, utilizándose las imágenes satelitales Landsat TM 5 y los sistemas de información geográfica. Para la identificación y evaluación de actividades, se consideraron otras fuentes de información primaria como entrevistas estructuradas, análisis documental y bibliográfico, observación directa del uso del suelo en el territorio y discusión grupal. El uso y ocupación del territorio durante el periodo de evaluación fue fomentado por la producción de cultivos alternativos, erradicación del terrorismo y narcotráfico, tendencia de mercado internacional y débil gestión del territorio. El área evaluada representa 206143 hectáreas, con predominancia de áreas productivas, bosque secundario y primario, uso urbano y cuerpos de agua. Las principales zonas de uso actual son de carácter productivo, con predominio de arroz, maíz, café, cacao, papaya, coco, piñón, tabaco, soya, sorgo, ganadería, y agricultura diversificada. .

PALABRAS CLAVE: socioeconómico, uso actual, Zonificación Ecológica Económica, ocupación del territorio.

\section{ASSESSMENT OF SOCIOECONOMIC PROCESSES OF THE USE AND OCCUPATION OF LAND IN THE PROVINCE OF PICOTA, SAN MARTIN, PERU, 1980 - 2012}

\begin{abstract}
The aim of this study was to evaluate the socioeconomic processes of the use and occupation of land in the province of Picota, San Martin. We determined current land use areas promoted by anthropic activities and other processes for the ten districts of the Province by using Landsant TM 5 satellite images and geographic information systems Other sources of primary information such as structured interviews, analysis of reports and publications, fieldwork and group discussion were used for the identification and evaluation of activities. The use and occupation of land was encouraged by the establishment of alternative crops, eradication of terrorism and drug traffic, international market trends and weak land management. The current extension of the study site is 2016143 hectares, with predominance of productive areas, secondary and primary forests, cities and water bodies. The main areas of current use are productive with plantations of rice, corn, coffee, cocoa, papaya, coconut, pine kernel, tobacco, soybean, sorghum, cattle raising, and diversification of crops.
\end{abstract}

KEYWORDS: Socioeconomic, Current Use, Ecological Economic Zoning, Occupation of land. 


\section{INTRODUCCIÓN}

Las actividades socioeconómicas desarrolladas en un determinado territorio son necesarias para la población (Meso ZEE, 2005). La Amazonía peruana, como parte del gran complejo de la cordillera Andina Oriental, se ha definido como un territorio muy accidentado, predominando el paisaje montañoso. En el departamento de San Martín se han determinado once actividades predominantes, siendo las más importantes la agricultura, la ganadería y la actividad forestal. En la provincia de Picota existen diversidad de recursos que son aprovechados para las diferentes actividades, sin embargo, se han identificado distintos problemas ambientales asociados al manejo inadecuado de estos recursos. Estos problemas están relacionados con el cambio de uso de la tierra, repercutiendo en la sostenibilidad de las actividades así como en los beneficios sociales y económicos que han transformado profundamente la oferta ambiental. (Macro ZEE, 2005). El estudio de estos procesos se puede optimizar con los sistemas de información geográfica, permitiendo conocer la magnitud, calidad y valor de la tierra, lo que la convierte en una herramienta indispensable para el análisis espacial y temporal. Para lograr resultados que sirvan como instrumentos de gestión, se evaluaron las dinámicas y las principales actividades socioeconómicos de la provincia, a partir de la descripción de los procesos producidos en una escala de tiempo priorizada, lo que permitió a su vez, evaluar la sostenibilidad del uso y la ocupación ordenada del territorio en armonía con las condiciones del ambiente, a través de un proceso progresivo de corto, mediano y largo plazo, enmarcados en una visión de logro provincial.

Esta escala de tiempo priorizada incluye procesos ejecutados en la provincia de Picota, como son la carretera Fernando Belaunde Terry, el puente Picota (sobre el río Huallaga), los canales de irrigación, etc., que han generado diversos impactos, propiciando incluso la deforestación, cultivo de hoja de coca, sembríos de maíz, arroz y el incremento de migración, sin conocer las diferentes consecuencias que podrían producir en el tiempo. Por esta razón, la investigación tuvo como objetivo determinar las zonas de uso actual del territorio generadas por las actividades antrópicas, identificando las actividades que motivaron el uso y ocupación del territorio, proponiendo medidas de gestión que contribuyan a la sostenibilidad del proceso socioeconómico en la provincia de Picota (Meso Picota, 2006).

\section{MATERIALES Y MÉTODOS}

\section{Área de estudio}

La provincia de Picota se encuentra ubicada en el sureste del departamento de San Martín, en el sector oriental de la Amazonía peruana (Figura 01). Limita al norte con las provincias de San Martín y Lamas, al este con el departamento de Loreto, al sur con la provincia de Bellavista y al oeste con la provincia de El Dorado. Tiene una extensión de 2171.41 kilómetros cuadrados y se divide en diez distritos: Picota, Buenos Aires, Caspisapa, Pilluana, Shamboyacu, Tingo de Ponasa, San Cristobal, Pucacaca, Tres Unidos, San Hilarión.

La presente investigación corresponde al tipo descriptivo. La técnica de obtención de información es de corte transversal temporal, utilizando los datos disponibles en el periodo de tiempo de 1.980 al 2.012, seleccionando solo los procesos que contribuyeron al incremento de las actividades socioeconómicas de la provincia: deforestación, sembríos de coca, arroz, maíz e inmigración.

\section{Población y muestreo}

La población estuvo conformada por la totalidad de procesos socioeconómicos ocurridos en la provincia de Picota desde el año 1.980 al 2.012, mientras que la muestra la conformaron los procesos socioeconómicos ocurridos en la provincia de Picota desde el año 1.980 a 2.012 priorizados: migración, deforestación, terrorismo, cultivo de hoja de coca, maíz y arroz. La técnica de muestreo adoptada fue la sistemática preferencial (se ordenaron la toma de muestras teniendo en cuenta su accesibilidad), aplicando el criterio no probabilístico (criterio basado y estandarizado teniendo en cuenta la experiencia del investigador en campo), identificándose en zonas representativas la ocurrencia de manifestaciones socioeconómicas importantes: tipos de cultivo, áreas, accesibilidad, entre otros.

\section{Instrumentos de recolección de datos}

\section{Entrevista Estructurada}

Se realizaron entrevistas estructuradas, tanto a las autoridades de los distritos de la provincia de Picota, para obtener información sobre los proyectos que se vienen ejecutando, como a los agricultores migrantes de zonas priorizadas, con la finalidad de conocer las razones que los motivaron instalarse y desarrollar sus actividades en la provincia de Picota. 


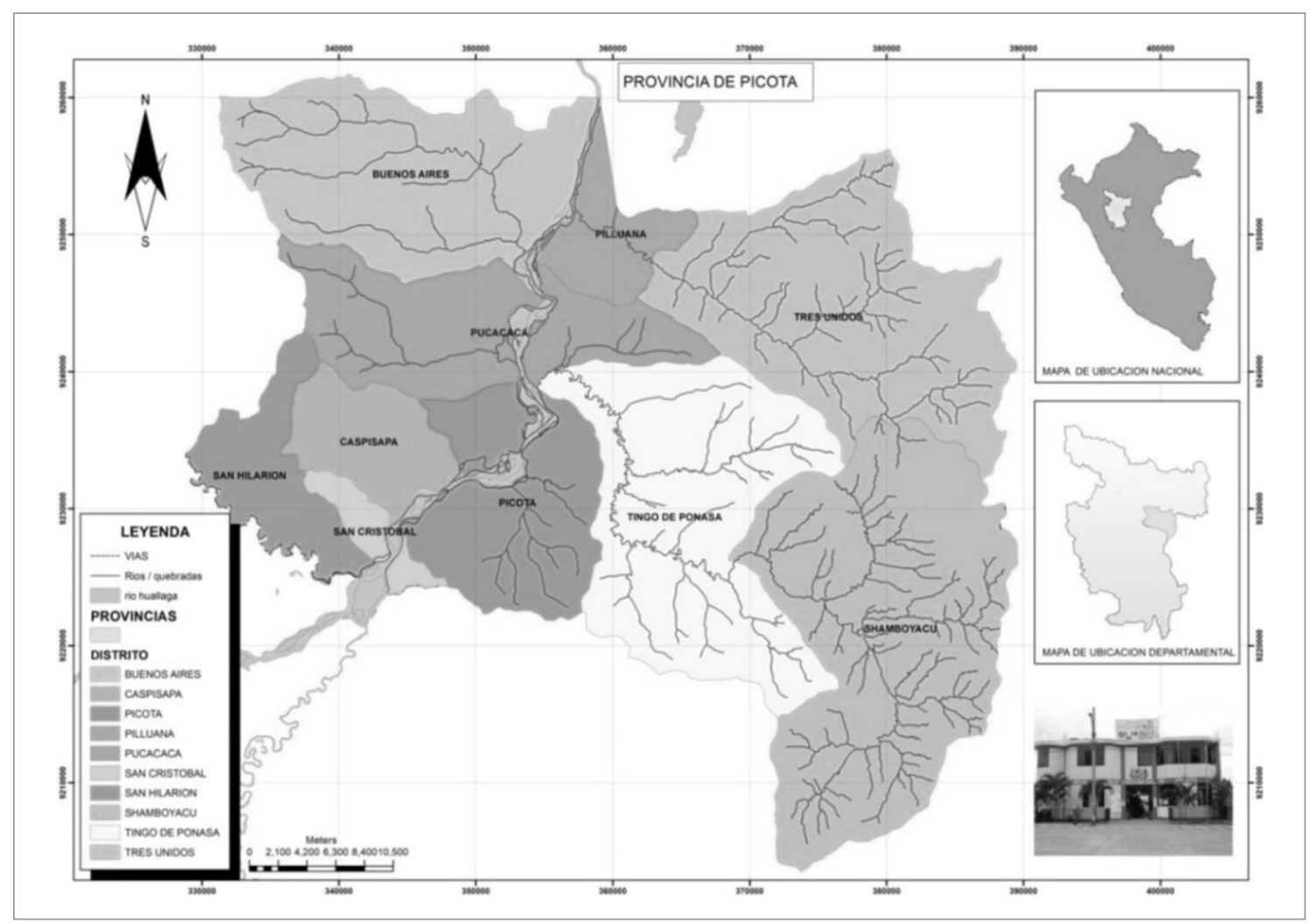

Figura 1. Ubicación de los puntos de colecta de individuos en la CC. NN. Bufeo Pozo.

\section{Análisis Documental y Bibliográfico}

Se analizaron documentos como la Zonificación Ecológica Económica a nivel Macro (Regional) y Meso (Picota), además de documentos técnicos elaborados por el Programa de Desarrollo Agro Ambiental en la Ceja de Selva (PROCEJA) y del Proyecto de Desarrollo Alternativo, así como publicaciones regionales y nacionales. Para el desarrollo de la propuesta de instrumentos de gestión, se recopiló información secundaria en las instituciones públicas y privadas con jurisdicción provincial, preferentemente en la capital. La secuencia de actividades fue la identificación de los instrumentos de gestión generados territorial y temporalmente en la provincia de Picota y el análisis del nivel de implementación de los instrumentos de gestión ambiental provincial.

\section{Observación directa del uso del suelo en el territorio}

Las salidas de campo permitieron analizar los procesos influenciados por los proyectos de inversión pública y otros factores, especialmente los relacionados a las actividades agrícolas. Las salidas de campo también sirvieron para contrastar las observaciones con las imágenes satelitales, siendo necesario para ello georeferenciar las áreas de interés y tomar datos en una matriz relacionados a las características u observaciones especiales.

\section{Discusión Grupal}

Se realizó con el equipo de trabajo del Programa de Investigación en Cambio Climático, Desarrollo Territorial y Ambiente (PROTERRA) / Programa de Investigación en Biodiversidad Amazónica (PIBA) San Martín. Las discusiones se realizaron de manera permanente, antes y después de las salidas de campo, para analizar los mapas y resultados obtenidos, así como para sustentar el avance de la investigación.

\section{Procesamiento y análisis}

Análisis de la información satelital

(Almacenamiento de las imágenes satelitales y selección de bandas espectrales). La Teledetección permitió detectar los cambios en las áreas de estudio. Para obtener información acerca de sus orígenes o sus causas se optó por combinarla con otros datos del Sistema de Información Geográfica 
(SIG). Las imágenes satelitales fueron Landsat TM5 2005,2007 y 2009. Con la finalidad de observar las imágenes satelitales se creó un archivo en formato img en el disco C. Esta imagen tiene de manera predeterminada las bandas 1,2,3, cuya resolución no es la más adecuada; es por ello que se modificó el espectro convirtiendo a la banda 1 en 4 y a la 2 en 5 , dando como resultado una imagen con la secuencia de bandas 4, 5,3. Esta combinación fue la que finalmente encajó con las características deseadas de color y las que facilitaron el análisis.

\section{Digitalización de las entidades de Uso Actual}

Con las bandas espectrales mejoradas, se inició el proceso de digitalización, que consistió en seleccionar las zonas de interés de acuerdo a sus características visuales (cobertura vegetal, uso agropecuario, zona urbana y cuerpos de agua). Se continuó con la demarcación poligonal y finalmente con el almacenamiento en shapes en función de las características identificadas. La digitalización es un proceso que requiere aplicar criterios de diferenciación visual, teniendo en cuenta no solo la característica de la imagen, sino también la georeferenciación y las características observadas en campo.
Procesamiento de la información en formato digital y fisico

La información secundaria fue sistematizada, organizada y almacenada en formato digital con la utilización del Office 2007 (Word y Excel), para el análisis de la información histórica-temporal.

\section{RESULTADOS}

\section{Determinación de las zonas de uso actual del territorio generado por las actividades antrópicas}

En la Figura 2, se presentan las áreas de cultivos comerciales, considerándose aquellos que se producen para el mercado externo a la provincia tales como: arroz, maíz, café, cacao, papaya, soya, sorgo, coco, piñón y tabaco. La información satelital arroja un área total de 48.857.03 Ha, que representan el $23.70 \%$ de la provincia.

\section{A. Cobertura vegetal presente}

Bosques primarios. Representan las áreas de bosques que no han sido intervenidas para usos agrícolas o cualquier otra actividad y que generalmente están ubicadas en las partes más altas del territorio, manteniendo su estado natural en su

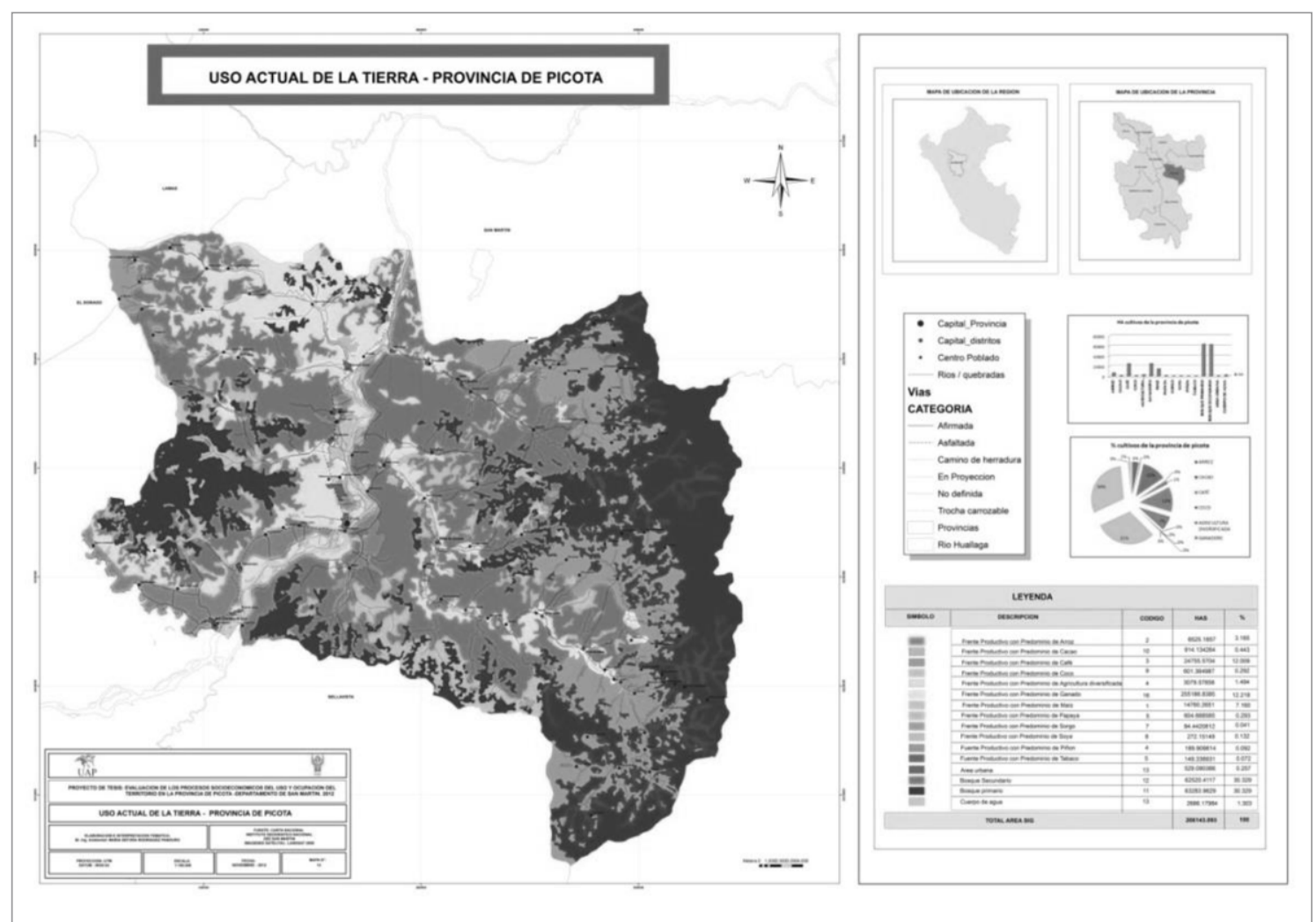

Figura 2. Mapa del Uso Actual de la Tierra en la provincia de Picota 2012. Fuente: Elaboración Propia Proyecto MOSTT. 


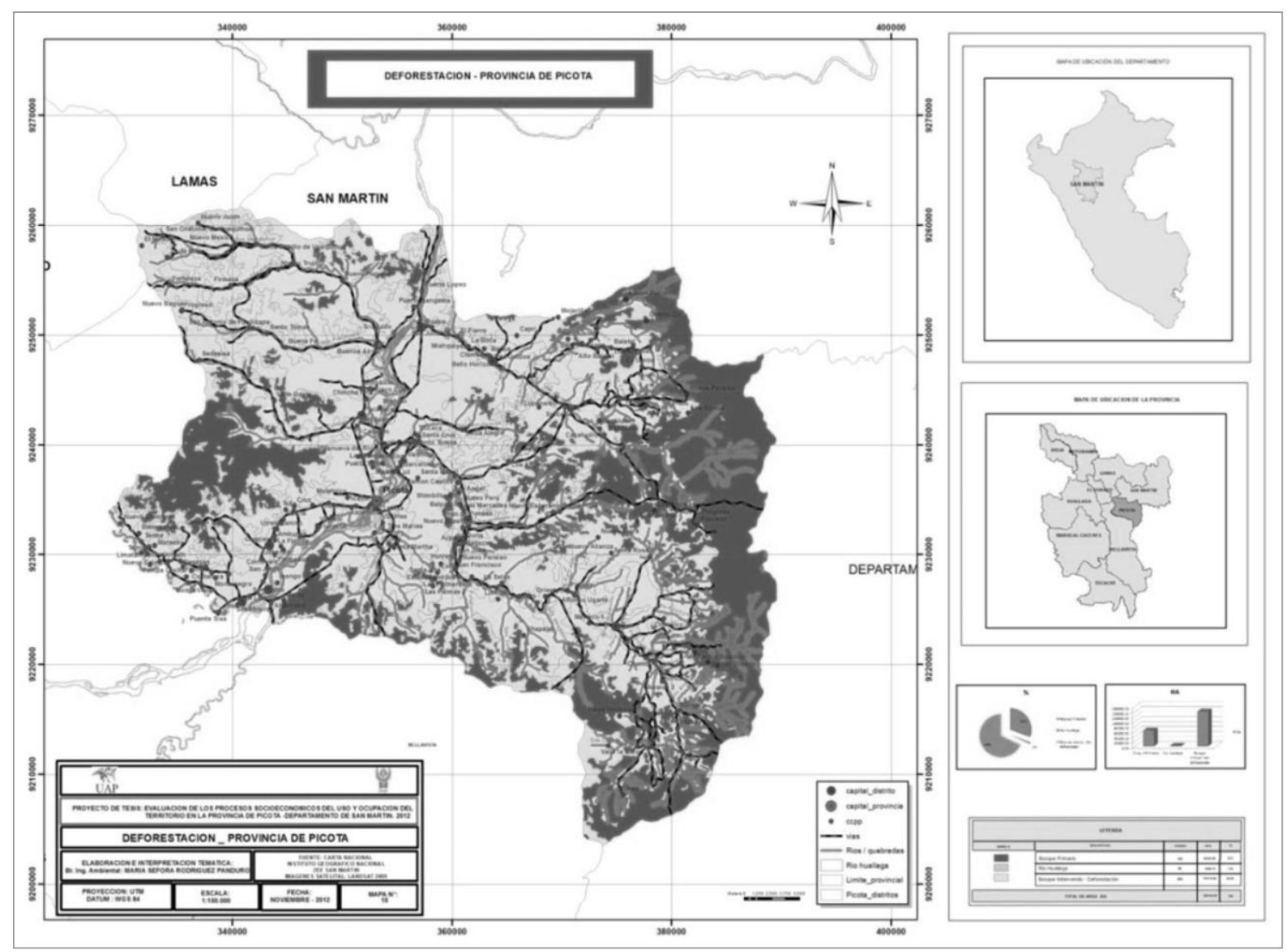

Figura 3. Mapa de Deforestación en la provincia de Picota. 2012. Fuente: Elaboración Propia Proyecto MOSTT.

composición boscosa. Se han encontrado un total de 63283 Ha que representa el $30.69 \%$ del total de área de la provincia.

Áreas naturales protegidas. Las Áreas Naturales Protegidas en la Provincia abarcan el $7.45 \%$ de su extensión total. Un gran porcentaje de la extensión la ocupa el Parque Nacional Cordillera Azul, ubicado en los distritos de Shamboyacu y Tres Unidos, así como otras Áreas de Conservación Municipal (ACM), como Quinillal, ubicada en los distrito de Tingo de Ponasa y Picota (2 273.44 hectáreas) y Ojos de agua, ubicada en el distrito de Pucacaca y Villanueva, creadas con el fin de proteger cabeceras de cuencas importantes como fuentes de abastecimiento de agua, bosques remanentes y paisajes de belleza escénica. Por otro lado, en la Figura 03, se muestra el estado de deforestación en el que se encuentra la provincia de Picota, con un total de 170172.95 Ha que representan el 68\%, a diferencia del bosque primario que sólo se observa $63283.96 \mathrm{Ha}$ (30.6 \%); siendo el menor espacio el ocupado por el río Huallaga con 2686.18 Ha (1.30 $\%)$. Es necesario precisar que se considera como zona deforestada a todas las áreas intervenidas, tales como centros poblados, cultivos agrícolas, bosque secundario, pastos, entre otros. El proceso desordenado de ocupación, identificado como el origen principal de los problemas ambientales producidos en la provincia de Picota, originó los siguientes impactos principales: deforestación, posible pérdida de la biodiversidad, disminución del caudal de las fuentes hídricas, fragmentación de ecosistemas y pérdida acelerada de la cultura tradicional.

B. Descripción de los principales impactos ambientales producidos en la provincia de picota por el uso y ocupación del territorio.

Los impactos ambientales producidos en la provincia de Picota por el uso y ocupación del territorio pueden agruparse en cinco grandes impactos, de los que podrían desprenderse algunos más. Sin embargo, la condición más importante es la identificación del proceso mayor, proceso conocido como Migración.

La migración se define como el proceso de traslado o desplazamiento del lugar de origen hacia otro que brinde mejores condiciones para satisfacer las necesidades básicas o secundarias. 
Es por ello que, desde el punto de vista de origen, puede clasificarse como emigración (proceso de salida del lugar) o inmigración (proceso de llegada hacia un lugar)

Identificando a este proceso desordenado como el origen principal de los problemas ambientales producidos en la provincia de Picota, se pudo priorizar los siguientes impactos:

Deforestación. La provincia de Picota desde el punto de vista de los recursos naturales, se caracteriza por poseer ecosistemas especiales como el bosque seco tropical y los bosques húmedos en las partes más altas. En estos se pueden identificar aún especies importantes desde el punto de vista forestal como la quinilla (Amburana cearensis), caoba (Swietenia macrophylla King), tornillo (Cedrelinga catenaeformis), moena (Aniba amazonica Meiz), estoraque (Myroxylon $s p$ ), entre otros. La demanda de estos recursos provocó la presión de extracción ilegal desmesurada sobre el recurso forestal, propiciando la apertura de trochas, generación de asentamientos humanos e inicio del proceso de cambio de uso de los espacios deforestados. La deforestación en la provincia fue incrementándose a medida que se mejoraban las condiciones de accesibilidad, como caminos vecinales y trochas carrozables, más aún con la construcción del puente sobre el río Huallaga, permitiendo la interconexión de la capital con el productivo valle del Ponasa y Mishquiyacu. (Programa de Desarrollo Agroambiental en la Ceja de Selva, 2011). La extracción de madera selectiva originó, a su vez, la instalación de un sin número de aserraderos en la capital, originando un incremento temporal del movimiento comercial de la zona. Otra causa que propició la deforestación está relacionada con la ampliación de la frontera agrícola, en especial para los cultivos de arroz y maíz y posteriormente papaya en la parte baja, mientras que en las partes altas el principal motivo fue la generación de fincas del café en un inicio además de cacao en la actualidad. (Escobedo, 2009).

Posible pérdida de la biodiversidad. La intervención de los ecosistemas por actividades antrópicas en la provincia también ha venido originando de manera directa e indirecta la posible pérdida de la biodiversidad. La pérdida indirecta se produce en actividades como la deforestación, la ampliación de la frontera agrícola y el incremento de la población fundamentalmente, por tratarse de actividades de presión sobre los recursos naturales que condicionan su disponibilidad y posible pérdida de la biodiversidad, en especial de aquellas especies con hábitat restringido o endémicas, por ser éstas las más vulnerables y las de menor resiliencia a la presión antrópica. Algunos ejemplos de estos efectos en la provincia se encuentran en la restricción de los hábitats de animales silvestres que anteriormente eran capturados y consumidos con mayor facilidad ("carne del monte") y sus depredadores, en especial felinos. Desde el punto de vista de la vegetación, se puede apreciar la disminución significativa de Platicerium andinum "helecho cuerno de venado", Pteridofito endémica de San Martín y de hábitat epífito en los bosques secos tropicales Huallaga Central. (MESO ZEE Picota. 2009).

La posible pérdida de manera directa está más relacionada con la extracción selectiva de los recursos, es decir, se escoge la especie hasta disminuirla al nivel de no encontrarla accesible geográfica y económicamente. La extracción de la quinilla (Amburana cearensis), caoba (Swietenia macrophylla King), tornillo (Cedrelinga catenaeformis), moena (Aniba amazonica Meiz), estoraque (Myroxylon sp), entre otras, son los ejemplos más característicos de este tipo de extracción. (Salas, 2009). Entre las principales consecuencias directamente relacionadas:

- Disminución del caudal de las fuentes hídricas. La disminución de la cobertura vegetal origina consecuentemente la disminución de la capacidad de retención de agua por el suelo, causando que las precipitaciones pluviales pasen casi de manera directa de la superficie hacia los cauces. Este proceso ocasiona que el caudal de los ríos y quebradas se incrementen muy rápidamente, pero también disminuyan prácticamente a la misma velocidad. Teniendo en cuenta la pérdida de caudal por evaporación, el aprovechamiento del agua por las poblaciones para consumo humano y el uso agrícola, da como resultado un mayor uso del recurso en función de su tasa de retorno o renovación. (Pinedo, 2009).

- Fragmentación de ecosistemas. La intervención en el territorio por diferentes actividades generan fragmentos que los caracterizan, pudiéndose observar espacios o parches que en conjunto ejercen el efecto de fragmentación en unidades prácticamente individuales. Este proceso tiene como consecuencia el aislamiento de las especies en cada fragmento, produciendo la limitación en la distribución natural de los organismos, aislamiento reproductivo y finalmente endogamia. (Rengifo, 2009).

En el territorio de Picota puede observarse un nivel de intervención de $170172.95 \mathrm{Ha}$, que representa el $68 \%$, vale decir, casi $2 / 3$ del total se encuentra fragmentado por las actividades humanas. Es por ello que cabe la posibilidad de que los procesos anteriormente descritos se estén 


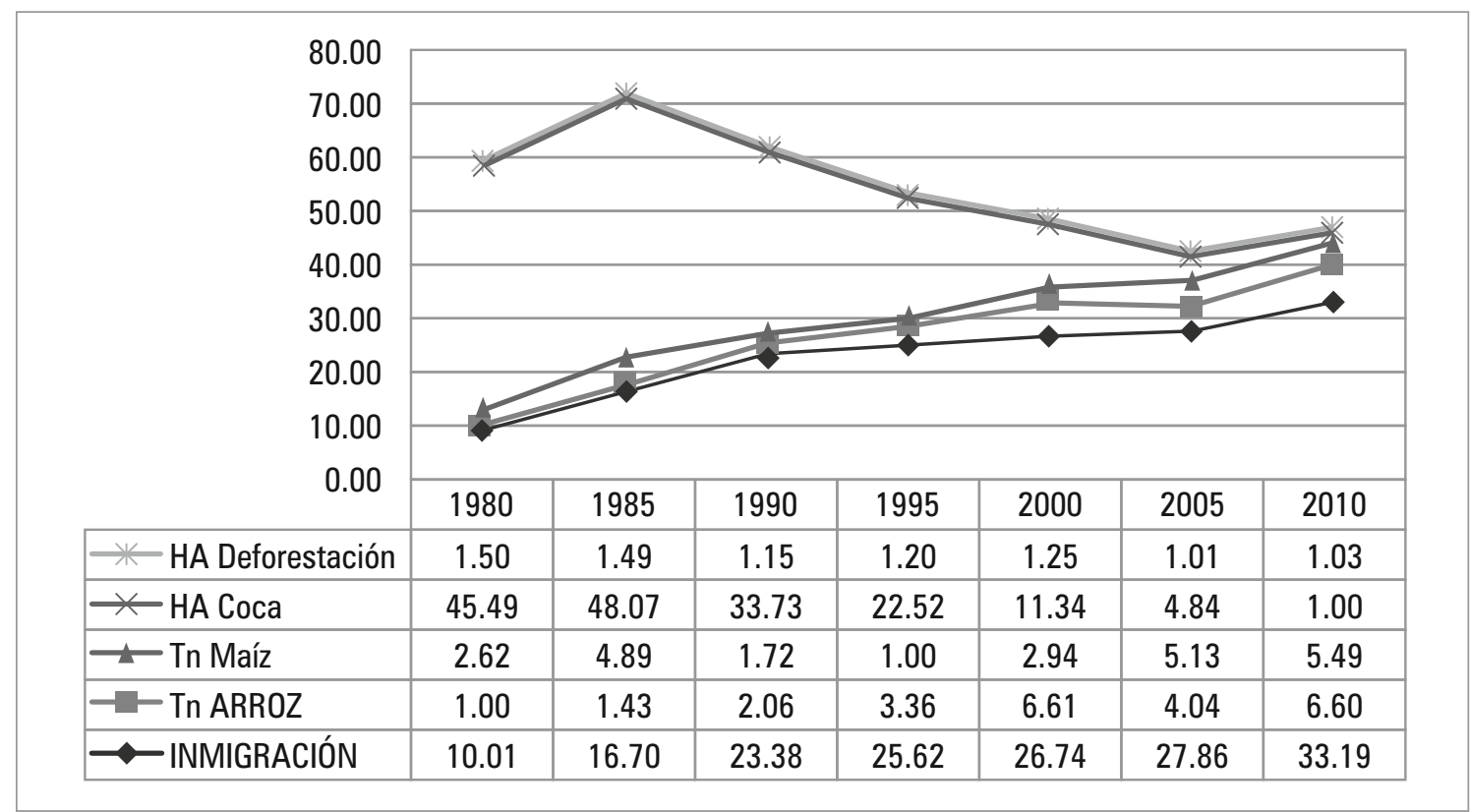

Figura 4. Uso de la tierra y ocupación del territorio en la provincia de Picota. Fuente: Elaboración Propia a partir de Macro ZEE.2007, Carranza et al., 2012, UNODC, PEAM y IIAP.

produciendo en los diferentes ecosistemas de la provincia, más aun teniendo en cuenta el informe temático de Biodiversidad de la Meso ZEE, en la que se reconoce la posibilidad de algunas especies nuevas y por lo tanto endémicas de la provincia. (Rengifo et al., 2009)

- Mestizaje. La inmigración hacia la provincia de Picota se ha incrementado en el año 1.980 (17 090) y el año 2.010 (248 935), con población proveniente de la sierra de los departamentos de Cajamarca, Piura y Amazonas; esta característica ha motivado que se inicie un proceso de mestizaje con las poblaciones originarias de nuestro departamento, teniendo como resultado que las prácticas, creencias y actividades tradicionales empiecen a desaparecer o se integren a las de los foráneos de manera, por lo general, poco intercultural.

Por lo general, este mestizaje provoca la adopción de prácticas poco sostenibles en espacios de selva, generando problemas ambientales importantes y generando la pérdida de recursos naturales de suma importancia para la supervivencia de muchas de las comunidades de la región.

\section{Identificación de las actividades que motivaron el uso y ocupación del territorio.}

A. Proceso de uso de la tierra y ocupación del territorio. Los cambios de uso de la tierra en la provincia de Picota, se han dado principalmente por la búsqueda de mejores condiciones de vida, trayendo como consecuencias una serie de conflictos tanto políticos, sociales y ambientales. La tasa de crecimiento en el periodo censal de 1981/1993 de los distritos de Buenos Aires, Pilluana, Pucacaca y Tingo de Ponasa fue negativa, lo que se relaciona a procesos socioeconómicos que influenciaron de manera directa, tales como el terrorismo y el narcotráfico (sembrío de hoja de coca). El primero de ellos originó también que la inversión se detenga, causando incluso que los empresarios y organizaciones se retiren, abandonando en muchos casos la infraestructura y maquinaria productiva (Federación Agraria Selva Maestra, Maíz Picota, entre otros). El sembrío de la hoja de coca, como actividad ilegal, durante los años de mayor apogeo del narcotráfico (década de los años 90), fue en muchos centros poblados la única actividad económica, causando una mejora temporal e irreal de sus economías; los sembríos tenían que ubicarse cada vez más en el interior de bosques primarios, causando deforestación, además de contaminación por agroquímicos (Oficina de las Naciones Unidas contra la droga y el delito UNODC. 2010). Las políticas antidrogas impuestas por el Estado a partir de los años 90, propiciaron una paulatina disminución de los sembríos. A su vez, se aplicaron diversas estrategias antiterrorismo, lo que fue facilitando la captura de los principales líderes y disminución significativa de sus actividades. 
Con el terrorismo y el narcotráfico controlado, la tasa de crecimiento poblacional se incrementó, periodo intercensal 1993 - 2007, en el que la Provincia tuvo $39.9 \%$ de incremento, creciendo a un ritmo promedio anual de 2.43\% (769 habitantes/ año), manteniéndose la tasa negativa solo en Pilluana (PROCEJA, 2011).

Este proceso de incremento poblacional se debe exclusivamente a la migración proveniente durante los últimos años de Cajamarca, Amazonas, Piura, Loreto y La Libertad preferentemente, motivada por la búsqueda de mejores condiciones de vida, oportunidades favorecidas por la ejecución de Proyectos como la construcción del canal de irrigación Sisa, la construcción del Puente Picota y la construcción de vías de acceso en la margen derecha del río Huallaga. Ello motivó incluso que los migrantes se posesionen de tierras destinadas a la protección y conservación, para dedicarlas al cultivo del arroz y el maíz, incorporándose después los cultivos de cacao, café y papaya, como los más representativos (incluso dentro del Parque Nacional Cordillera Azul).

En el gráfico anterior se observa que en el año 1980 existieron cambios en el uso y ocupación del territorio, determinándose el incremento de la deforestación y los sembríos ilícitos (cultivo de hoja de coca). Así mismo, a partir de 1985, se incrementan los sembríos de maíz y arroz, incrementando la inmigración y originando problemas de carácter social en la provincia.

\section{B. Proyectos de Inversión Pública en la provincia de Picota.}

En el año 2006 se creó la Oficina de Inversión Pública (OPI) en la provincia, desde ese año hasta la actualidad se han registrado ciento sesenta y ocho proyectos en diferentes procesos (viable, en formulación, modificación y en evaluación), de los cuales ciento catorce se encuentran específicamente como viables. Sin embargo, no podemos precisar el nivel en que se encuentran, es decir, su estado de ejecución o si ya fueron concluidos.

\section{Propuesta de medidas de gestión que pueden contribuir a la sostenibilidad del proceso socioeconómico en la provincia de picota.}

Se identificaron acciones e instrumentos de gestión a la espera de implementación:
A. Zonificación Ecológica Económica. Se deberá continuar con el procedimiento para la elaboración de la ZEE de la provincia de Picota, terminando las etapas contempladas en el Reglamento de ZEE (Decreto Supremo 087-2004- PCM).

B. Comisión Ambiental Municipal. De acuerdo a la Ley del Sistema Nacional de Gestión Ambiental (LEY $\mathrm{N}^{\circ}$ 28245) y el Decreto de Creación del Ministerio del Ambiente (Decreto Legislativo $\mathrm{N}^{\circ}$ 1013), se establece la necesidad de conformar las Comisiones Ambientales Municipales en cada gobierno local, con la finalidad de contar con una instancia de coordinación, promoción, iniciativa y asesoramiento en materia ambiental dentro de la jurisdicción política.

C. Plan de Acción Ambiental y Agenda Ambiental Local. Estos dos instrumentos de gestión son los primeros que deben plantearse después de elaborar el Diagnóstico y la Política Ambiental, teniendo como objetivos la planificación a largo, mediano y corto plazo de las actividades tendientes a solucionar y/o mitigar la problemática ambiental local.

D. Propuesta de Plan de Acción Ambiental. En vista que aún la Provincia de Picota no cuenta con el Plan de Acción Ambiental aprobado, teniendo como soporte los documentos ya avanzados en las diferentes instituciones y siendo de singular importancia el contar con este instrumento de gestión, es que se sugiere a la Municipalidad Provincial su inmediata priorización y elaboración en función a la normativa ambiental vigente.

\section{DISCUSIÓN}

De acuerdo a la evaluación realizada en treinta y cuatro centros poblados de la provincia de Picota, se determinó, de acuerdo a su orden de importancia actual, ocho frentes representativos, con predominio del arroz, maíz, café, cacao, papaya, coco, soya, sorgo, piñón, tabaco, ganado y agricultura diversificada, en la que se encuentra el sembrío de plátano, piña, pastos y caña brava. Históricamente, los cultivos que marcaron el inicio del importante cambio socioeconómico en la provincia fueron el arroz y el maíz, seguidos del café y cacao, que viene mostrando un incrementando permanente debido a la tendencia internacional del mercado, la calidad y certificación del producto; se ha convertido también en un modelo a ser aplicado en otros lugares puesto que sus inicios se fundamentan en la promoción como cultivo alternativo a los sembríos de hoja de coca.

Los datos de superficie de los cultivos obtenidos, al compararlos con los de la Dirección Regional de Agricultura (DRA), muestran diferencias numéricas bastante notorias. Se asume que se debe a las metodologías de recojo de información. Para el primero de los casos el dato en hectáreas obedece a 
una interpretación de combinación de bandas y área para un tipo específico de cultivo, convirtiendo posteriormente estas superficies en estándares de producción para cada caso; sin que ello necesariamente exprese el nivel de productividad asociado al manejo que puede darle cada propietario; mientras que los datos de la DRA se obtienen a partir de un volumen de producción que son convertidos en hectáreas promedio de acuerdo a las condiciones temporales específicas.

Por otro lado, la ocupación desordenada del territorio que se viene dando en la Provincia, se debe a su débil gestión y la insuficiente aplicación de procedimientos normativos orientados al control de actividades ilegales. Sin embargo, también es necesario mencionar que existen procesos e iniciativas que podrán mejorar esta condición, tales como la Meso Zonificación Ecológica Económica, la implementación de actividades del Programa de Desarrollo Agroambiental en la Ceja de Selva (PROCEJA) y las actuales exigencias internacionales de mejora de los productos orgánicos.

Contrariamente, la ocupación del territorio trae consigo también impactos ambientales, los que se producen por la débil implementación de estrategias destinadas a la regulación de las actividades antrópicas en espacios no adecuados o incompatibles con las potencialidades del espacio. La inmigración hacia las cabeceras de cuenca, la deforestación y la disminución de los caudales hídricos, son los impactos más comunes en toda la provincia, que a la larga han originado degradación de suelos, pérdida de biodiversidad y fragmentación de ecosistemas. Estos se han ido incrementando en proporción a las mejoras en las condiciones socioeconómicas relacionadas a las generadas por los cultivos como café y cacao en los últimos tiempos y al inicio favorecido por los sembríos de maíz y arroz.

Con el análisis temporal de las imágenes satelitales $(2005,2007$ y 2009) y las salidas de campo, pudimos constatar variaciones en todos los distritos y prácticamente para todos los cultivos, sin que ello signifique que obedezcan a algún patrón fijo (precio de los cultivos), condiciones ambientales (tipo de suelos, ausencia o presencia de lluvias) o facilidades de infraestructura (vías, riego, entre otros). Vale decir, que los cambios observados son totalmente aleatorios y no tendenciales, resaltándose que en la mayoría de los casos coincidió con el incremento del área para todos los cultivos, además del aumento de los espacios deforestados.

Por otro lado, los procesos socioeconómicos que se vienen desarrollando en la provincia de Picota tienen su origen en actividades que propiciaron, primero el incremento del flujo migratorio $\mathrm{y}$ segundo la implementación de cultivos diferentes a los tradicionalmente practicados, ello se evidencia al interrelacionar los factores (Gráfico $\mathrm{N}^{\circ}$ 01): deforestación, sembríos ilícitos (sembrío de coca), arroz, maíz e inmigración; pudiendo identificar con mayor facilidad, el punto de origen del mayor crecimiento socioeconómico en la provincia: disminución de Ha de sembrío de coca y tasa de deforestación, frente al incremento de la inmigración y las hectáreas de cultivos de maíz y arroz. En ese mismo sentido, las pérdidas de áreas de bosque primario, se relaciona con el incremento de la densidad poblacional en las cabeceras de cuenca. Paralelo a ello, se propiciaron aperturas de mercado para productos orgánicos, siendo el café el que ofertó las mejores condiciones.

La ocupación del territorio también se presentó en función a las vías y las fuentes de agua superficiales, verificao a través del análisis fotométrico, debido a las facilidades de intercomunicación y traslado del producto, la disminución del tiempo y costos de transporte (para el caso de las vías) y proximidad a contar con el recurso para satisfacer las necesidades básicas de consumo humano (para el caso del agua).

\section{CONCLUSIONES}

El proceso socioeconómico en la provincia de Picota se inició de manera aleatoria en sus diez distritos en la década de los $80^{\prime}$, con actividades asociadas a la deforestación, sembríos de coca, arroz, maíz e inmigración. Las principales zonas de uso actual del territorio de la provincia de Picota son de carácter productivo, con predominio de arroz (6 525.18 Ha que representa el $3.16 \%$ de la provincia), Maíz (1 4760. $26 \mathrm{Ha}$-7.16\%), Café (24 755.57-12 009\%), cacao $914.13 \mathrm{Ha}-0.44 \%)$, papaya (604.66 $\mathrm{Ha}-0.29 \%)$, Coco (601.36 Ha - 0.29\%), Piñón $(189.90 \mathrm{Ha}-0.09 \%)$, Tabaco (149.33 Ha-0.07\%), Soya $(272.15 \mathrm{Ha}-0.13 \%)$, sorgo $(84.44 \mathrm{Ha}-$ 0.04\%), Ganadería (25 186.43 Ha - 12.210\%), Diversidad (3 $079.57 \mathrm{Ha}-1.494 \%$ ), Bosque Primario (63 $283 \mathrm{Ha}-30.69 \%$ ), Uso Urbano $(529.09 \mathrm{Ha}-0.25 \%)$. Mientras que la deforestación representa el $68 \%$ (170 172.95 Ha).

Se identificó que las principales actividades que motivaron el uso y ocupación del territorio de la provincia de Picota en los últimos años fueron la extracción de madera (deforestación), sembrío de coca, arroz y maíz, así como la inmigración, además de las mejoras de las condiciones e infraestructura y servicio social generados recientemente (ciento catorce proyectos de inversión viables en los diez 
distritos de la provincia de Picota desde el año 2006 hasta 2012). Del análisis de los instrumentos de gestión se identificaron avances tanto institucionales como documentarios, tales como: PROCEJA, ZEE, Plan de Desarrollo Concertado, pero se carece de los instrumentos de planificación ambiental, por lo que se sugiere implementar un Plan de Acción Ambiental Provincial.

\section{AGRADECIMIENTOS}

Al Proyecto Mejoramiento de la Oferta del Servicio de Transferencia Tecnológica en el Instituto de Investigaciones de la Amazonía Peruana - IIAP San Martín - Propuesta de Valoración de los Proyectos de Investigación del IIAP San Martin, por el financiamiento para la ejecución del presente estudio. A la Universidad Alas Peruanas, Filial Tarapoto y al Centro de Investigación, Gestión y Consultoría Ambiental-CEICAS.A.C. San Martín.

\section{BIBLIOGRAFÍA CITADA}

Barkin, D. 1998. Riqueza, pobreza y desarrollo sustentable. Editorial Jus y Centro de Ecología y Desarrollo. México. 50 pp total.

Bernal, M. 2007. Cambio de uso del suelo rural a urbano y su relación con el medio ambiente en el municipio de Coacalco de Berriozábal, Estado de México. Instituto Politécnico Nacional. México (http://itzamna.bnct.ipn.mx:8080/ dspace/bitstream/123456789/1424/1/2459_200 7 CIIEMAD MAESTRIA bernal sanchez $\mathrm{m}$ ariahaydee.pdf). Acceso: 10/10/12.

Centro de Conservación, Investigación y Manejo de Área Naturales. (2010). Propuesta de Microzonificación Ecológica y Económica en el sector de Shamboyacu. San Martín.

Carranza, L; Gallardo, Jy Vidal, R. 2012. Las barreras al crecimiento económico en San Martín. Consorcio de Investigación Económica y Social. Perú. (http://cies.org.pe/files/ documents/otras-inv/libro-San-Martin-pdf). Acceso: 05/06/12.

Escobedo, Roger. 2009. Estudio de suelos y capacidad de uso mayor de las tierras de la provincia de Picota. Perú.

García, J.; Novak, F. 2010. El problema del narcotráfico en el Departamento San Martín. Pontificia Universidad Católica del Perú. 44 pp total.
García, J.; Novak, F. 2010. El problema del narcotráfico en el Departamento San Martín. Pontificia Universidad Católica del Perú. (http://idei.pucp.edu.pe/docs/sanmartin.pdf). acceso: 12/09/12.

Macro Zonificación Ecológica Económica. Uso actual de suelo. 2005 .

Meso Zonificación Ecológica Económica. Eso Actual de suelo. 2009

Oficina de las Naciones Unidas contra la Droga y el Delito. 2006. El modelo de desarrollo Alternativo del Departamento de San Martín. Perú. 207 p.

Pacco, E. 2012. Capacidad de uso mayor para determinar los conflictos de uso de la tierra en el micro cuenca Picuro yacú. Universidad Nacional Agraria de la Selva. Tingo María. 137 p.

Programa de Desarrollo Agroambiental en la Ceja de Selva. Proyecto Manejo Forestal Agroforestal en las cuencas de Mishquiyacu y Ponaza. 2010.

Pinedo, R. 2009. Evaluación y caracterización del potencial hidrográfico para el proceso de formulación de la propuesta de ZEE de la provincia de Picota. Gobierno Regional de San Martin. Perú. (http://www.google.com.pe/ url? $\mathrm{sa}=\mathrm{t} \& \mathrm{rct}=\mathrm{j} \& \mathrm{q}=\&$ esrc $=\mathrm{s} \& \mathrm{frm}=1 \&$ source $=$ web\&cd $=1 \&$ cad $=$ rja\&ved $=0$ CCoQFjAA\&url $=$ http $\% 3 \mathrm{~A} \% 2 \mathrm{~F} \% 2 \mathrm{Fdocs}$.seace.gob.pe $\% 2 \mathrm{Fmon} \%$ 2Fdocs\%2Fprocesos\%2F 2008\%2F000050\%2F 000487 MC-38-2008-SERVICIOSBASES.doc \&ei=Po5JUomuNIic9QT72oDYDg\&usg $=$ AFQ jCNH1J eHr ItjOIF2UrQzQTaQPzM81w \&sig2 $=$ d_IaJ6ÖoPJr53z49MBhabQ\&bvm=bv. 53217764,d.eWU). Acceso: 02/11/12.

Rengifo, C; Peso, M; Rabanal, H. 2009. Estudio de Caracterización del Uso Actual de la Tierra (Incluyendo conflictos de uso de la provincia de Picota. Instituto de Investigaciones de la Amazonía Peruana. Perú. $61 \mathrm{p}$.

Salas, Greta. 2009. Elaboración y Evaluación de la situación actual y del potencial forestal para el proceso de formulación de la propuesta de ZEE de la provincia de Picota. Perú.

\section{Recibido: 21 de agosto del 2015}

Aceptado para publicación: 10 de noviembre del 2015 